\title{
Health behaviors and family characteristics in early childhood influence caries development. A longitudinal study based on data from $\mathrm{MoBa}$
}

\author{
Tove I. Wigen and Nina J. Wang \\ Department of Pediatric Dentistry and Behavioral Science, Institute of Clinical Dentistry, University of Oslo, Norway \\ Correspondence: Tove I. Wigen, E-mail: wigen@odont.uio.no Telephone: +4722852041 / +4722852000
}

\begin{abstract}
Background: Lifestyle diseases including dental caries are partly preventable, and associated with health behavior. Establishing favorable health behavior is one main challenge both in general and dental health services. The purpose of this paper was to focus on cross-disciplinary research that has the potential to prevent development of both dental caries and other lifestyle diseases. More specifically the aim was to study how family characteristics and health behavior in pregnancy and early childhood influence caries development in preschool children.

Material and methods: Data from dental examination of 5 year old children in the public dental services was linked to data from MoBa. In total, 1348 children were followed from pregnancy to 5 years of age. The data has provided opportunity to follow longitudinally the development of oral health behavior in early childhood in a large sample, and to study associations between caries development during preschool age and information in the MoBa database.

Results: Results from the studies showed that tooth brushing frequency established at 1.5 year of age was stable through preschool age. Caries development in preschool age was related to child and maternal risk behavior in early childhood and to characteristics of risk families.

Conclusion: Cross-disciplinary research using MoBa data has given new knowledge on dental caries development in early childhood in Norway. This knowledge can be used in clinical practice both in general and dental health services to improve preventive efforts towards early childhood caries and other lifestyle diseases.
\end{abstract}

This is an open access article distributed under the Creative Commons Attribution Licence, which permits unrestricted use, distribution, and reproduction in any medium, provided the original work is properly cited.

\section{INTRODUCTION}

Dental health is an integral part of general health and wellbeing. In Norway, there has been and still is limited collaboration between general and dental health services, both in clinical practice and in research. Dental personnel and health personnel have separate educations. Medical doctors and dentist in Norway have some joint pre-clinical training while one study has shown that the public health nurses' curriculum regarding oral health was random and limited (1).

Dental caries is still one of the most common diseases in children. Caries prevalence is reduced during the last decades, and the distribution has become skewed, with a minority of the children having the majority of the carious lesions (Figure 1) (2-5). In Norway, one of three 5 year old children has caries experience, $18 \%$ has manifest caries requiring restorations and $29 \%$ has initial caries that require treatment with fluoride and dietary advice to prevent the carious process from further development and need for restorations. Some children have both initial and manifest caries (Figure 2) (5). There are numerous risk indicators associated with caries development in preschool children; both socioeconomic status, feeding habits and early colonization of caries bacteria has been linked to caries development (6). In Norway, documentation of association between caries prevalence in preschool children and risk indicators is limited to few studies on selected populations $(7,8)$. Previous caries experience has been considered the best predictor of future caries development in children (9), but this predictor is not useful for children having their first carious lesion.

Dental caries is a lifestyle disease. Lifestyle diseases such as obesity, heart disease, diabetes and oral diseases share a set of common risk factors (Figure 3) (10). Factors such as poor-quality diet, tobacco smoking, inadequate hygiene and trauma are linked to the development of several chronic conditions including oral diseases (11).

Oral health conditions influence general health and wellbeing and vice versa. A healthy mouth enables nutrition, enhances social interaction and promotes self-esteem and feeling of well-being. Untreated dental caries may affect body weight, growth and quality of life in preschool children $(12,13)$. The mouth serves as a "window" to the rest of the body, providing signals of general health disorders. Bacteria from the mouth may cause infections in other parts of the body when the immune system is compromised by disease or medical treatment (14). Systemic conditions and their treatments are known to impact oral health; reduced salivary flow may lead to increased risk of dental caries and reduced ability to perform dental hygiene 


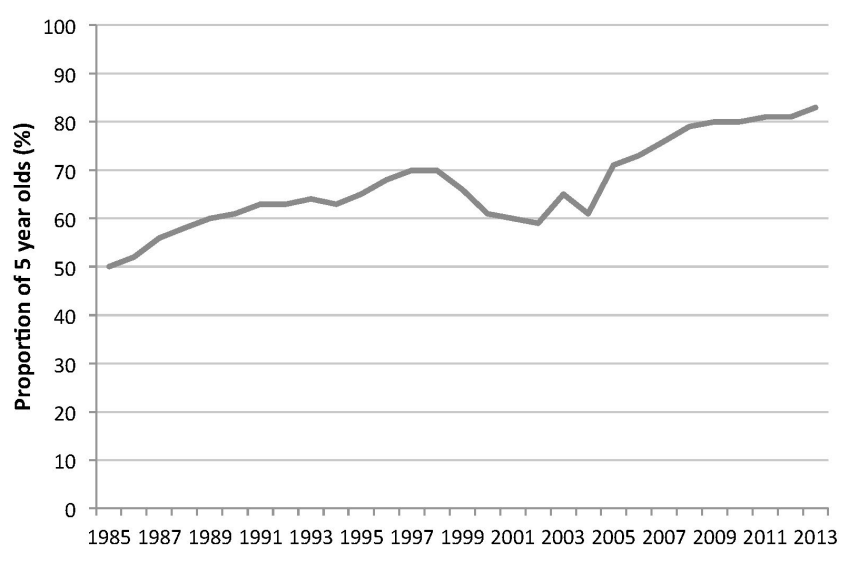

Figure 1. Proportion of 5 year old children without manifest caries experience in Norway from 1985 to 2013 (2).

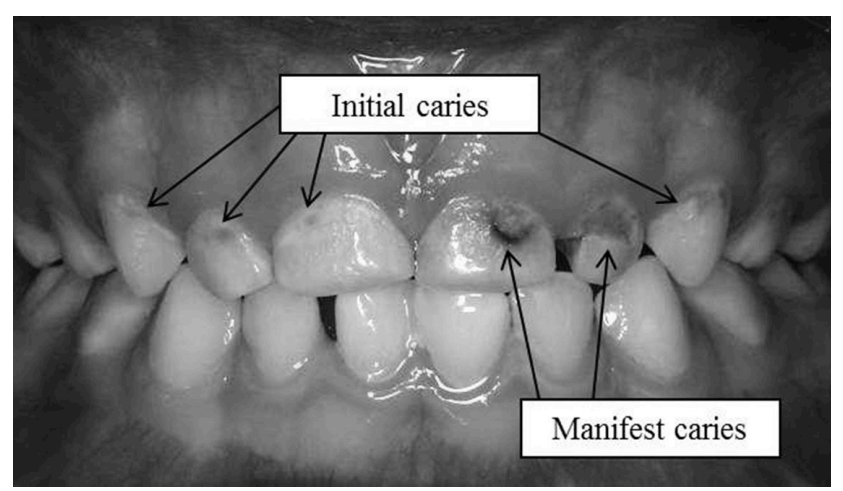

Figure 2. Initial and manifest carious lesions in 5 year old child.

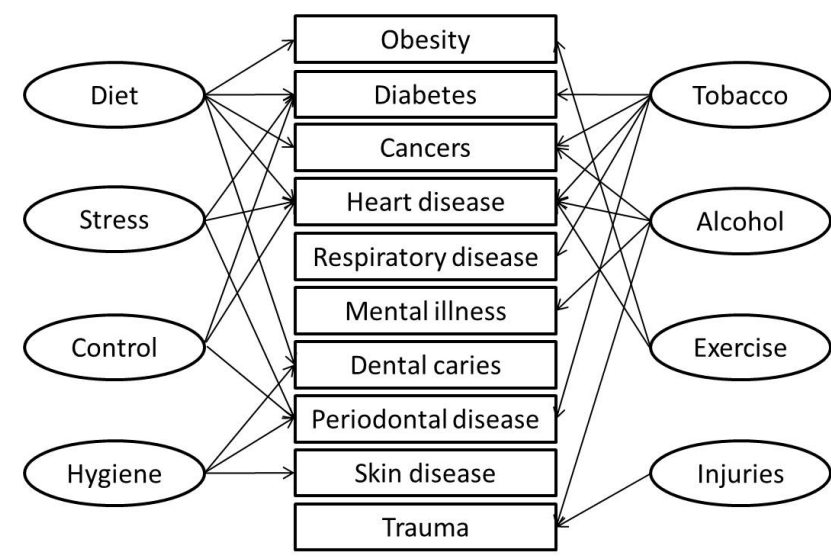

Figure 3. Lifestyle diseases and common risk factors modified from Sheiham et al (10).

during illness may be detrimental to dental health (15).

Lifestyle diseases including dental caries are partly preventable, and associated with health behavior. Establishing favorable health behaviors is one main challenge both in general and dental health services. Early initiation of preventive efforts is paramount to minimize the risk of lifestyle disease. Changing unfavorable dietary habits and especially sugar intake is a common challenge to both general and dental health services $(16,17)$. Oral health programs are often developed in isolation from other health initiatives. Uncoordinated approaches lead to duplication of advice and may result in conflicting and contradictory messages being delivered to the public. Although national guidelines exist (18), limited knowledge is available about the information given by different health professionals in Norway and if the information given is consistent.

Health information is supposed to be evidencebased, and research should be based on partnership between researchers in several health disciplines, as in the Mother and Child Cohort Study (MoBa). The purpose of this paper was to focus on cross-disciplinary research that has the potential to prevent development of both dental caries and other lifestyle diseases. More specifically the aim was to study how family characteristics and health behavior in pregnancy and early childhood influence caries development in preschool children. This paper summarizes results from four previously published papers using MoBa-data and data from the Public Dental Services.

\section{MATERIAL AND METHODS}

The objective of the Mother and Child Cohort Study $(\mathrm{MoBa})$ is to test specific etiological hypotheses by estimating the association between exposure and disease, aiming at prevention (19). When the MoBa study was designed, questions of oral health behavior, tooth brushing frequency and use of fluoride in early childhood were included. This has given the opportunity to use the database in research regarding caries development in preschool children.

The studies were based on MoBa quality-assured data files (version 3) released for research in 2007, and were restricted to children born in 2002 in the county of Akershus. Altogether, 1607 children were included, that was $27 \%$ of the children born in Akershus in 2002. Clinical data collected from dental examination in 2007 and 2008 in the Public Dental Services was obtained from 1366 children. Eighteen children were excluded from the analyses because of incomplete data. The final study population consisted of 1348 children. The data provided opportunity to follow longitudinally the development of oral health behavior from 1.5 to 5 years of age in a large sample, and to study association between information in the MoBa database and caries development during preschool age (20-24). The data includes information about maternal health and health behavior, family characteristics such as education, national origin, family situation and economy.

The statistical analyses were performed using IBM SPSS, version 20. Bivariable and multivariable logistic regression analyses were conducted with having caries experience at age 5 years of age as the dependent variable in three of the studies $(20,21,23)$, while stable brushing from 1.5 to 5 years of age, and stable use of 
fluoride lozenges from 1.5 to 5 years of age were dependent variables in one study (22).

Written, informed consent was obtained from all parents. The investigation was approved by the Regional Committee for Medical Research Ethics in SouthEastern Norway and the Norwegian Data Inspectorate.

\section{RESULTS}

\section{Longitudinal oral health behavior}

The results showed that at 1.5 years of age only half of the children had their teeth brushed twice daily, although the health authorities recommend tooth brushing twice daily with fluoridated tooth paste from eruption of the first tooth $(22,25)$. When exploring the longitudinal development of oral health behaviors from 1.5 to 5 years of age, the results showed that tooth brushing frequency established in early childhood, at 1.5 years of age, were stable through preschool age. Children who had their teeth brushed twice daily at 1.5 years more often brushed twice daily at 3 years of age $(\mathrm{p}<0.001)$, and at 5 years of age $(\mathrm{p}<0.001)$ than other children. Children having both parents of western origin or having one older sibling were more likely to be stable frequent brushers than other children (22). Similar results were found when exploring longitudinal the development of use of fluoride lozenges. Children having established one favorable oral health behavior more often had several favorable oral health behaviors. Children having their teeth brushed twice daily at 1.5 years of age more often used fluoride lozenges than children having the teeth brushed less than twice daily $(\mathrm{p}=0.03)(22)$.

\section{Child and maternal risk behavior and caries}

The results showed that low tooth brushing frequency at 1.5 year of age and frequent consumption of sugary drinks at 1.5 year of age were related to high caries prevalence at 5 years of age when controlling for family characteristics (Table 1) (23).

When exploring association between maternal diet and caries development in children the results showed that having mother who consumed more sugar and fat than recommended, were associated with caries development in children during preschool age. Having mother with BMI classified as obese was associated with caries development in children before 5 years of age (Table 1) (21).

\section{Caries risk families}

With MoBa data, we have been able to explore characteristics of the family and the mothers during pregnancy and caries development in children during preschool age. The results from the studies showed that having mother with low education and having mother with non-western background was associated with caries development in children before 5 years of age. A change in family situation from two to one parent family before child age 5 years was associated with caries development in children (Table 1) (20).
Table 1. Summary of results of multivariable logistic regression analyses. Associations between oral health behavior at 1.5 year of age (23), maternal health and lifestyle (21) and family characteristics (20) and caries experience in 5 year old children.

\begin{tabular}{|c|c|c|}
\hline & OR & $95 \% \mathrm{CI}$ \\
\hline \multicolumn{3}{|l|}{ Oral health behaviour at 1.5 year of age } \\
\hline \multicolumn{3}{|l|}{ Tooth brushing frequency } \\
\hline \multicolumn{3}{|l|}{ Twice daily or more often (ref) } \\
\hline Less than twice daily & 2.3 & $1.4-3.7$ \\
\hline \multicolumn{3}{|l|}{ Sugary drinks } \\
\hline \multicolumn{3}{|l|}{ Less than once a week (ref) } \\
\hline At least once a week & 1.7 & $1.1-2.8$ \\
\hline \multicolumn{3}{|l|}{ Sugary drinks at night } \\
\hline \multicolumn{3}{|l|}{ Never (ref) } \\
\hline Sometimes & 1.5 & $0.8-2.8$ \\
\hline Each night & 2.2 & $1.1-4.5$ \\
\hline \multicolumn{3}{|l|}{ Maternal health and lifestyle } \\
\hline \multicolumn{3}{|l|}{ Maternal dietary sugar (\% of energy intake) } \\
\hline$\geq 10$ & 1.5 & $1.1-2.3$ \\
\hline \multicolumn{3}{|l|}{ Maternal dietary fat ( $\%$ of energy intake) } \\
\hline \multicolumn{3}{|l|}{$<35(\mathrm{ref})$} \\
\hline$\geq 35$ & 1.6 & $1.1-2.5$ \\
\hline \multicolumn{3}{|l|}{ Maternal BMI } \\
\hline \multicolumn{3}{|l|}{ Normal (ref) } \\
\hline Overweight & 1.6 & $1.0-2.5$ \\
\hline Obese & 2.3 & $1.3-4.1$ \\
\hline \multicolumn{3}{|l|}{ Family characteristics } \\
\hline \multicolumn{3}{|l|}{ Maternal education } \\
\hline \multicolumn{3}{|l|}{ High (ref) } \\
\hline Low & 1.5 & $1.1-2.3$ \\
\hline \multicolumn{3}{|l|}{ Parental origin } \\
\hline \multicolumn{3}{|l|}{ Both western (ref) } \\
\hline One or both non-western & 5.4 & $2.8-10.6$ \\
\hline \multicolumn{3}{|l|}{ Family status from pregnancy to age 5} \\
\hline No change (ref) & & \\
\hline Change from two to one parent family & 2.0 & $1.1-3.4$ \\
\hline
\end{tabular}

\section{DISCUSSION}

The results from the studies identify areas where collaboration between the general and dental health services would facilitate establishment and maintenance of healthy lifestyles. The general health services have information about the family and the mother such as national origin, education, family situation, economy, maternal health and lifestyle even before the child is born, that can be used to identify children at risk of acquiring early childhood caries.

During pregnancy and the first years of life parents and children have regular contact with the general health services. These studies have shown that establishment of frequent tooth brushing at 1.5 years of age is maintained during early childhood and is associated with reduced caries prevalence. Families with young children having difficulties establishing tooth brushing twice daily from eruption of first tooth should be referred from the general health services to the dental health services to acquire caries prevention. The dental health services have established systems for collaboration with the public health centers, but the knowledge 
about how these systems work in practice is not documented.

Later in childhood, after the age of 3 years children have regular contact with the dental health services. Collaboration between the general health services and the dental health services may enforce the coordination of lifestyle advice given to families with children. At present dental personnel give advice about diet to prevent dental caries and use of tobacco and snuff for adolescents to prevent periodontitis and oral cancer $(26,27)$. For some families this may result in conflicting advice from dental personnel and medical personnel, leading to confusion. Coordination of advice given, may improve chances of changing unfavorable health behavior which may lead to reduced risk of developing lifestyle diseases in later life. Frequent contact between medical and dental personnel, ex- change of information and coordination of routines is essential to facilitate collaboration.

\section{CONCLUSION}

Cross-disciplinary research using $\mathrm{MoBa}$ data has given new knowledge on oral health behavior and dental caries development in early childhood in Norway. This knowledge can be used in clinical practice both in general and dental health services to improve preventive efforts towards early childhood caries and other lifestyle diseases.

\section{ACKNOWLEDGEMENT}

We would like to thank Professor Emeritus Harald M. Eriksen who during planning of the MoBa study ensured inclusion of questions about dental health.

\section{REFERANSER}

1. Skeie MS, Skaret E, Espelid I, Misvaer N. Do public health nurses in Norway promote information on oral health? BMC Oral Health 2011;11:23.

2. Statistics Norway. Dental status by age. 2014. https://www.ssb.no/statistikkbanken/SelectTable/hovedtabell Hjem.asp?KortNavnWeb=tannhelse\&CMSSubjectArea=helse \&StatVariant=\&PLanguage $=1 \&$ checked=true . Accessed 02.06.2014.

3. Selwitz RH, Ismail AI, Pitts NB. Dental caries. Lancet 2007;369:51-9.

4. Vehkalahti M, Tarkkonen L, Varsio S, Heikkila P. Decrease in and polarization of dental caries occurrence among child and youth populations, 1976-1993. Caries Res 1997;31:161-5.

5. Wigen TI, Wang NJ. Caries and background factors in Norwegian and immigrant 5-year-old children. Community Dent Oral Epidemiol 2010;38:19-28.

6. Harris R, Nicoll AD, Adair PM, Pine CM. Risk factors for dental caries in young children: a systematic review of the literature. Community Dental Health 2004;21:71-85.

7. Grytten J, Rossow I, Holst D, Steele L. Longitudinal study of dental health behaviors and other caries predictors in early childhood. Community Dent Oral Epidemiol 1988;16:356-9.

8. Skeie MS, Riordan PJ, Klock KS, Espelid I. Parental risk attitudes and caries-related behaviours among immigrant and western native children in Oslo. Community Dent Oral Epidemiol 2006;34:103-13.

9. Mejare I, Axelsson S, Dahlen G, Espelid I, Norlund A, Tranaeus S, Twetman S. Caries risk assessment. A systematic review. Acta Odontol Scand 2014;72:81-91.

10. Sheiham A, Watt RG. The common risk factor approach: a rational basis for promoting oral health. Community Dent Oral Epidemiol 2000;28:399-406.

11. Watt RG. Strategies and approaches in oral disease prevention and health promotion. Bull World Health Organ 2005;83:711-8.

12. Sheiham A. Dental caries affects body weight, growth and quality of life in preschool children. $\mathrm{Br}$ Dent $J$ 2006;201:625-6.

13. Pine CM, Harris RV, Burnside G, Merrett MC. An investigation of the relationship between untreated decayed teeth and dental sepsis in 5-year-old children. Br Dent J 2006;200:45-7.

14. Costerton J, Keller D. Oral periopathogens and systemic effects. Gen Dent 2007;55:210-5.

15. Fejerskov O, Kidd E. Dental Caries. The Disease and its Clinical Management, 2. edn. Blackwell Munksgaard, 2008.

16. Lustig RH, Schmidt LA, Brindis CD. Public health: The toxic truth about sugar. Nature 2012;482:27-9.

17. Zero DT. Sugars - the arch criminal? Caries Res 2004;38:277-85.

18. The Norwegian Directorate of Health. Anbefalinger om kosthold, ernæring og fysisk aktivitet. Oslo, 2014. Report No. IS-2170.

19. Magnus P, Irgens LM, Haug K, Nystad W, Skjaerven R, Stoltenberg C. Cohort profile: the Norwegian Mother and Child Cohort Study. Int J Epidemiol 2006;35:1146-50.

20. Wigen TI, Espelid I, Skaare AB, Wang NJ. Family characteristics and caries experience in preschool children. A longitudinal study from pregnancy to 5 years of age. Community Dent Oral Epidemiol 2011;39:311-7. 
21. Wigen TI, Wang NJ. Maternal health and lifestyle, and caries experience in preschool children. A longitudinal study from pregnancy to age 5 yr. Eur J Oral Sci 2011;119:463-8.

22. Wigen TI, Wang NJ. Tooth brushing frequency and use of fluoride lozenges in children from 1.5 to 5 years of age. A longitudinal study. Community Dent Oral Epidemiol 2014;42:395-403.

23. Wigen TI, Wang NJ. Does early establishment of favourable oral health behaviour influence caries prevalence at age 5 years? Acta Odontol Scand 2014, early online.

24. Wigen TI, Wang NJ. Parental influences on dental caries development in preschool children. An overview with emphasis on recent Norwegian research. Norsk Epidemiologi 2012;22:13-9.

25. The Norwegian Directorate of Health. Tenner for livet. Helsefremmende og forebyggende arbeid. Oslo, 1999. Report No. IS-2659.

26. Sand L, Wallstrom M, Hirsch JM. Smokeless tobacco, viruses and oral cancer. Oral Health Dental Manag 2014;13:372-8.

27. Calsina G, Ramon JM, Echeverria JJ. Effects of smoking on periodontal tissues. J Clin Periodontol 2002; 29:771-6. 